\title{
Land use impact on carbon mineralization is mainly caused by variation of particulate organic matter content rather than of soil structure
}

5 Reitz $^{1,2}$

\author{
Steffen Schlüter ${ }^{1}$, Tim Roussety ${ }^{1}$, Lena Rohe ${ }^{1}$, Vusal Guliyev², Evgenia Blagodatskaya ${ }^{2}$, Thomas
}

${ }^{1}$ Department Soil System Sciences, Helmholtz-Centre for Environmental Research - UFZ, Theodor-Lieser-Str. 4, 06120 Halle (Saale), Germany

${ }^{2}$ Department Soil Ecology, Helmholtz-Centre for Environmental Research - UFZ, Theodor-Lieser-Str. 4, 06120 Halle

(Saale), Germany

Correspondence to: Steffen Schlüter (steffen.schlüter@ufz.de)

Abstract. Land use is known to exert a dominant impact on a range of essential soil functions like water retention, carbon sequestration, matter cycling and plant growth. At the same time, land use management is known to have a strong influence on soil structure, e.g. through bioturbation, tillage and compaction. However, it is often unclear whether differences in soil structure are the actual cause for differences in soil functions or just co-occurring.

This impact of land use (conventional and organic farming, intensive and extensive meadow, extensive pasture) on the relationship between soil structure and short-term carbon mineralization was investigated the Global Change Exploratory Facility, in Bad Lauchstädt, Germany. Intact topsoil cores $(n=75)$ were sampled from each land use type at the early growing

20 season. Soil structure and microbial activity were measured using X-ray computed tomography and respirometry, respectively.

Grasslands had a greater microbial activity than croplands, both in terms of basal respiration and rate of carbon mineralization during growth. This was caused by a larger amount of particulate organic matter (POM) in the topsoil of grasslands. The frequently postulated dependency of basal respiration on soil moisture was absent even though some cores

25 were apparently water limited. This finding was related to microenvironments shaping microbial hotspots where the decomposition of plant residues was obviously decoupled from water limitation in bulk soil. Differences in microstructural properties between land uses were surprisingly small, mainly due huge variability induced by patterns of compacted clods and loose areas caused by tillage in cropland soils. The most striking difference was larger macropore diameters in grasslands soil due to the presence of large biopores that are periodically destroyed in croplands.

30 Variability of basal respiration among all soil cores amounted to more than one order of magnitude (0.08-1.42 $\mu \mathrm{g} \mathrm{CO}_{2}-\mathrm{C} \mathrm{h}^{-1}$ $\mathrm{g}^{-1}$ soil) and was best described by POM mass $\left(\mathrm{R}^{2}=0.53, \mathrm{p}<0.001\right)$. Predictive power was hardly improved by considering all bulk, microstructure and microbial properties jointly. The predictive power of image-derived microstructural properties was low, because aeration was not limiting carbon mineralization and was sustained by pores smaller than the image resolution 
https://doi.org/10.5194/soil-2021-56

Preprint. Discussion started: 22 July 2021

(c) Author(s) 2021. CC BY 4.0 License.

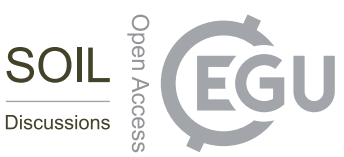

limit $(<30 \mu \mathrm{m})$. The rate of glucose mineralization during growth was explained well by substrate-induced respiration

$\left(\mathrm{R}^{2}=0.84\right)$ prior to growth, which was in turn correlated with total microbial biomass, basal respiration and POM mass and again not affected by pore metrics.

These findings stress that soil structure had little relevance in predicting carbon mineralization in well-aerated soil, as this predominantly took place in microbial hotspots around degrading POM that was detached from the pore structure and moisture of the bulk soil. Land use therefore affects carbon mineralization in well-aerated soil mainly by the amount and quality of labile carbon.

\section{Introduction}

Soil respiration is an important link in the global carbon (C) cycle as it releases soil-borne organic carbon back into the atmosphere. The balance between $\mathrm{C}$ storage and $\mathrm{C}$ mineralization is thought to arise from an interplay between the molecular diversity of organic compounds and the spatial heterogeneity and temporal variability of environmental conditions in soil (Lehmann et al., 2020). Soil moisture and temperature are considered to be the environmental factors that exert a dominant control on $\mathrm{C}$ mineralization either directly through their control on reaction and diffusion rates or indirectly through their effect on biomass production including plants and microfauna (Davidson et al., 2006). Land use related changes in soil management can affect carbon mineralization in all of the aforementioned ways, i.e. through changes in thermal properties, water retention and consumption as well as biomass production. The variability in carbon mineralization is thought to arise from differences in substrate accessibility and soil aeration due to soil structure changes that modify the size and spatial distribution of pores and, as a consequence, the exposure of organic carbon to microbial decomposition (Dungait et al., 2012;Schmidt et al., 2011). Despite their obvious importance, larger-scale C cycling models are just starting to incorporate these microscale interactions (Yan et al., 2018;Ebrahimi and Or, 2018;Meurer et al., 2020).

A major hurdle to fully account for structural constraints on $\mathrm{C}$ mineralization is the methodological challenge to combine

55 incubation studies with the investigation of soil microenvironments on identical samples. A viable option in this respect has emerged with microstructure analyses of incubated soil samples via X-ray computed microtomography (X-ray CT). By employing this combination of methods, the mineralization rate of the stable soil C pool turned out to depend on the average pore neck diameter as a proxy for soil aeration for a loamy forest soil with a range of bulk densities that was brought to the same water saturation and incubated for 35 days (Bouckaert et al., 2013). Long-term incubations (127 days) of silt-loam soils

60 with fixed bulk soil densities $\left(1.4 \mathrm{~g} / \mathrm{cm}^{3}\right)$ and soil moisture contents (matric potential pF 2.5, water content 25 vol\%), but very different internal structure (undisturbed, sieved, slaked) exhibited no differences in C mineralization rate after passing of the initial $\mathrm{CO}_{2}$ flush caused by disturbance irrespective of substrate amendment (fructose, vanillin) (Juarez et al., 2013). Even though the macropore space scanned at a coarse resolution $(32 \mu \mathrm{m})$ differed vastly between the structure treatments in terms of volume fraction and morphology, the pore space scanned at a finer resolution of $3 \mu \mathrm{m}$ was quite similar, indicating

65 that the continuity of air and water at this soil moisture and thus the supply with oxygen and dissolved substrates was too similar to evoke differences in $\mathrm{C}$ mineralization despite differences in microbial abundance and community composition at 
https://doi.org/10.5194/soil-2021-56

Preprint. Discussion started: 22 July 2021

(c) Author(s) 2021. CC BY 4.0 License.

(c) (i)

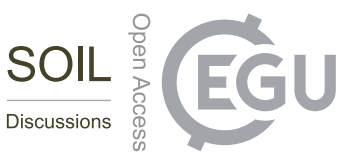

the end of incubation. Soil aggregates (5-6mm) from a clay soil, adjusted to a matric potential of pF 2.7 and incubated for 1 day showed a six-fold variation in soil respiration (normalized for differences in organic C content) at only a two-fold difference in organic carbon content (Rawlins et al., 2016). The internal pore surface area was best suited to explain the difference in respiration, yet only at a fairly moderate correlation coefficient $(\mathrm{R}=0.44)$. It has been suggested that the magnitude of protection of soil organic $C$ against mineralization results from the interplay of how much $C$ enters the soil as plant biomass and exudates and how much of this newly added C is subsequently protected (Kravchenko et al., 2019). This balance may be very different between different land uses and was shown, in a case study comparing continuous corn, switchgrass, and native succession, to depend on the plant-stimulated pore formation in the size range of $30-150 \mu \mathrm{m}$ as these pores are associated with the highest enzyme activities and thus the highest capacity for microbial transformation of carbon sources (Kravchenko et al., 2019). In summary, microstructure analysis may help to improve the prediction of carbon mineralization rates in intact soil. However, from the previous findings it is already evident that a true gain in predictability is not always warranted and depends on the environmental conditions encountered during incubation.

We therefore measured soil respiration under contrasting land uses (cropland vs. grassland) that are known to induce various

80 soil structures after exposing them to very different environmental conditions: 1 . basal respiration at field moisture and 2. substrate induced respiration (SIR) at higher soil moisture. The rationale for repeated incubations of intact soil cores at different moisture and substrate availability was to provide a more complete picture of links between microstructural properties and carbon mineralization. Our objectives were to 1) investigate differences in soil structure and C mineralization induced by land use and 2) to explore as how to far microstructural properties are required to explain carbon mineralization

85 rates. Bearing in mind that such microstructure analyses are laborious and time consuming, we 3) aimed to assess in how far these microstructural properties can be replaced by easily available bulk properties.

\section{Materials \& Methods}

\subsection{Site description}

The Global Change Experimental Facility (GCEF) is situated at the field research station of the Helmholtz Centre for

90 Environmental Research in Bad Lauchstädt, Germany (51²3'33.1"N 1152'56.5"E, $121 \mathrm{~m}$ a.s.l.). The site is characterized by a sub-continental, temperate climate with an annual mean temperature of $9.7{ }^{\circ} \mathrm{C}$ (1993-2013) and a mean annual precipitation of $525 \mathrm{~mm}$ (1993-2013). The soil type is a fertile Haplic Chernozem with on average 21\% clay, 69\% silt, and $10 \%$ sand in the topsoil layer (Altermann et al., 2005). The GCEF platform was established in 2013 and combines five land use types with two climate treatments (Schädler et al., 2019). The full design comprises 50 large field plots (16x24 m),

95 which are arranged in ten blocks. Five of the blocks are subjected to ambient climate, while five are exposed to conditions of a projected future climate. The five land use types were randomly assigned to the five plots of each block and include (1) conventional farming (CF), (2) organic farming (OF), (3) intensively managed grassland used by mowing (IM), (4) extensively managed grassland used by mowing (EM) and (5) extensively managed grassland used as sheep pasture (EP). Each treatment combination (land use $\mathrm{x}$ climate) is replicated five times across the experimental platform. The land use types 
https://doi.org/10.5194/soil-2021-56

Preprint. Discussion started: 22 July 2021

(c) Author(s) 2021. CC BY 4.0 License.

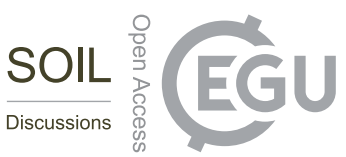

are managed according to common practices for Central Europe and include the full set of respective management measures (fertilizer and pesticide application, soil and plant cultivation). On CF plots a rapeseed-wheat-barley crop rotation is cultivated, whereas rapeseed is replaced by a legume in OF. For IM, a species-poor mixture of forage grasses was established, consisting of Lolium perenne (20\%), 'Festulolium' (50\%), Dactylis glomerata (20\%) and Poa pratensis (10 \%). In contrast, a mixture of 56 plants species from the local gene pool, containing legumes, grasses and non-leguminous dicots species, was sown in both extensively managed grasslands (EM, EP). The management of both croplands include conventional soil cultivation. For further details on treatments and management we refer to Schädler et al. (2019).

\subsection{Field sampling}

We focused on the 25 plots ( 5 land use types x 5 field replicates) exposed to ambient climatic conditions. Sampling took place in early May 2020, when plants in the cropland plots (CF: rapeseed, OF: white clover) were at the beginning of vegetation season. Intact soils cores were sampled with aluminum rings $\left(\mathrm{v}=100 \mathrm{~cm}^{3}, \mathrm{~h}=4 \mathrm{~cm}\right)$ in a depth between 3 and $10 \mathrm{~cm}$. Three soil cores were taken from each plot totaling 75 samples. After sampling, the soil cores were stored in bags under cool conditions, including the imaging procedure, until respirometry. Importantly, both croplands were plowed (18 ${ }^{\text {th }}$ of February) and further cultivated with a rotary cultivator ( $4^{\text {th }}$ of March) few months before sampling.

\subsection{Bulk properties}

115 Bulk density $(\rho)$ and initial water saturation $(\theta / \phi)$ were determined by weighing the soil cores before respirometry, as well as after drying the cores at $105^{\circ} \mathrm{C}$ for 48 hours following respirometry. Thereby bulk density was calculated with the final soil dry weight divided by the core volume $\left(100 \mathrm{~cm}^{3}\right)$. Water content $(\theta)$ in the collected soil cores were determined by mass differences of initial and final soil weights. Water saturation levels were obtained by normalizing the total water volume $(\theta)$ with total soil pore volume $(\phi)$. Air contents $\left(\theta_{a}\right)$ during substrate-induced respiration were calculated from the difference between $\phi$ and $\theta+\theta_{g l}$ after substrate-induced respirometry, with $\theta_{g l}$ representing the volumetric glucose solution content. Finally, to measure the contents of particulate organic matter (POM), roots and plant litter were washed out of the soil cores using a wet sieving procedure $\left(0.63 \mathrm{~mm}\right.$ mesh size). POM mass $\left(m_{r}\right)$ was determined after drying for 48 hours at $70^{\circ} \mathrm{C}$. Additional explanatory variables, i.e. total $\mathrm{C}$ and $\mathrm{C}: \mathrm{N}$ ratio, were determined for all plots using soil samples collected at the $20^{\text {th }}$ of March 2020 in the course of the continuous GCEF monitoring program. Total carbon and nitrogen contents were measured from sieved (2 mm) fine soil using an elemental analyzer (Elementar Vario EL III, Elementar, Hanau, Germany).

\subsection{Microstructure analysis}

All soil cores were scanned with X-ray computed tomography (X-tek XT H 225; Nikon Metrology) at 150kV and 170 $\mu$ A with 2500 projections and two frames per projection. A $0.3 \mathrm{~mm}$ copper filter was used to reduce beam hardening artefacts. Tomograms were reconstructed with 8-bit grayscale and $30 \mu \mathrm{m}$ voxel size with the X-tek CT Pro software (Nikon

130 Metrology). Gray scale contrast was stretched by setting the darkest and brightest 0.2 percentile to 0 and 255, respectively. All image processing was carried out with the Fiji bundle for ImageJ (Schindelin et al., 2012) and associated plugins. Image noise was reduced with a non-local means filter (Buades et al., 2005) prior to edge enhancement with an unsharp mask filter 
https://doi.org/10.5194/soil-2021-56

Preprint. Discussion started: 22 July 2021

(c) Author(s) 2021. CC BY 4.0 License.

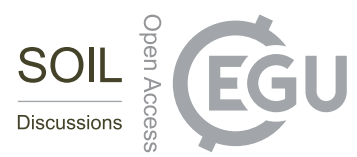

(Schlüter et al., 2014). The grayscale images were segmented into pores and background with Otsu's method (Otsu, 1975) for pore structure analysis at the original resolution. Pore metrics of interest include visible porosity ( $\phi_{\text {vis }}$ ), surface area density $(a)$, mean breadth $(b)$ and the Euler number density $(\chi)$, which were determined with the MorphoLibJ plugin (Legland et al., 2016). The pore topology metric $\chi$ counts the number of isolated pore objects positively and the number of redundant connections negatively, so that poorly connected and well-connected pore structures induce positive and negative, $\chi$, respectively (Vogel et al., 2010). A complementary connectivity metric is the connection probability $\Gamma$, which reflects the probability of two randomly chosen pore voxels to belong to the same pore cluster. Pore clustering was carried out with the connected components labelling in MorpholibJ (Legland et al., 2016). The average pore distance $(d)$ was determined based on the Euclidean distance transform of soil voxels, i.e. shortest distance to a pore for all background voxels. The average pore diameter $(\varnothing)$ was determined with the maximum inscribed sphere method termed Local Thickness in ImageJ (Fig. 1b). The critical pore diameter $\emptyset_{c}$ reflects the bottleneck diameter at which pore continuity from top to bottom is lost (Koestel, 2018).
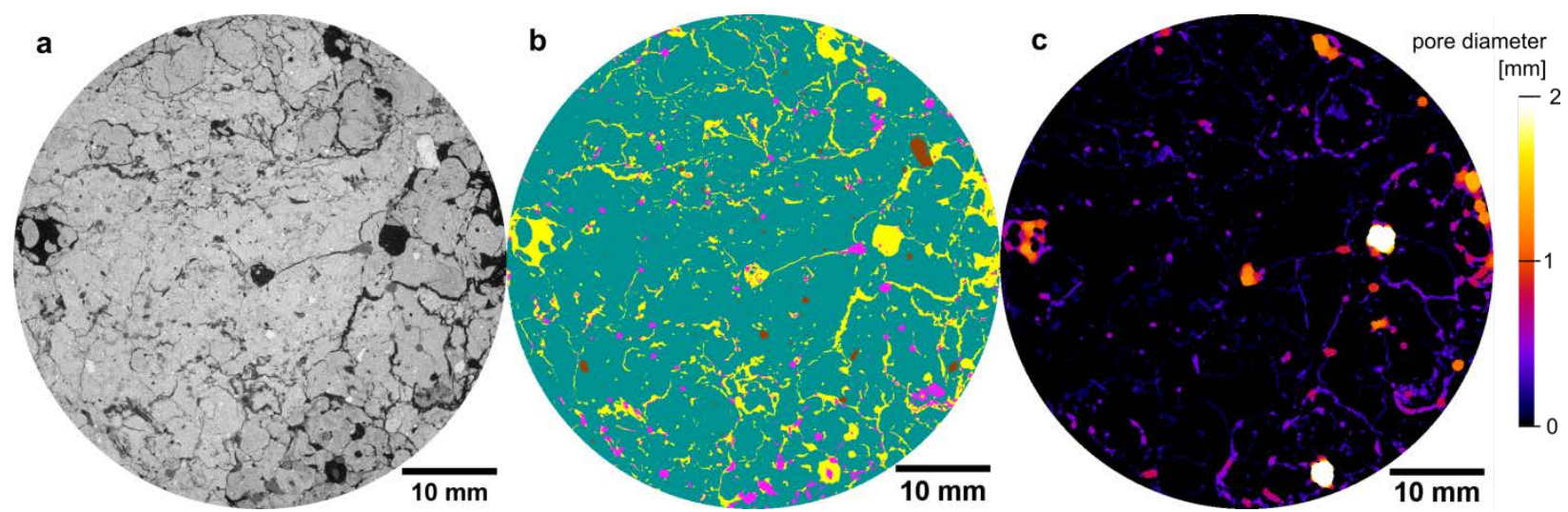

Figure 1: Visualization of image processing steps for a 2D section of an X-ray CT image from a) the gray scale data to b) image segmentation results based on supervised, machine-learning based segmentation (pores yellow, POM pink, matrix green, rocks brown) and c) pore diameters based on local thickness.

In addition to these pore metrics, the volume fraction of particulate organic matter (POM) was determined via supervised, machine-learning based image segmentation with ilastik (Sommer et al., 2011). A parallel random forest classifier was used to segment pores, POM, soil matrix and rocks (Fig. 1b) by deploying a multi-dimensional feature space that included the original gray values as well as gradient (1st derivative of gray values) and texture information (2nd derivative of gray values) after Gaussian smoothing with a strength of $\sigma=[0.3,0.7,1.0]$. In this way, characteristic traits of each material like the aperture of cracks, the inherent heterogeneity of the organic fabric or the homogeneity of quartz grains was harnessed for material detection. The classifier was trained with a few test lines for each material class in a small number of images (six out of 75). The images had to be downscaled to a voxel size of $60 \mu \mathrm{m}$ to make segmentation tractable.

\subsection{Respirometry}


https://doi.org/10.5194/soil-2021-56

Preprint. Discussion started: 22 July 2021

(c) Author(s) 2021. CC BY 4.0 License.

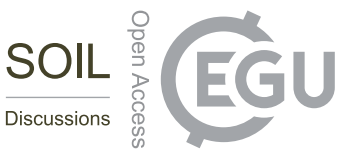

Basal respiration $\left(p_{B}\right)$ rates were determined from intact soil cores $\left(100 \mathrm{~cm}^{3}\right)$ at $22^{\circ} \mathrm{C}$ and field water saturation using an automated respiration analyzer (Respicond V, Sweden). Emitted $\mathrm{CO}_{2}$ is trapped in $10 \mathrm{~mL}$ of $0.6 \mathrm{M} \mathrm{KOH}$ solution and measured through the increase in electric impedance at a given voltage. Soil cores were incubated for two days and the average respiration rate determined for the period after some initial equilibration. Respirometry was conducted on 60 out of 75 soil cores distributed evenly among cropland (CF and OF, 15 each) and grassland soil (IM, EM and EP, 10 each).

The same 60 soil cores were subsequently amended with a glucose containing mineral salt solution (glucose $-0.28 \mathrm{M}$; $\left(\mathrm{NH}_{4}\right)_{2} \mathrm{SO}_{4}-0.07 \mathrm{M} ; \mathrm{KH}_{2} \mathrm{PO}_{4}-0.025 \mathrm{M} ; \mathrm{MgSO}_{4}-0.125 \mathrm{M}$ ) to measure substrate-induced respiration (SIR) (Anderson and Domsch, 1978) and to infer microbial growth kinetics from it (Stenström et al., 1998;Panikov, 1995). The solution was added to the field moist soil cores in two steps. First, the bottom of the soil cores was covered with a textile before placing them for 30min in the glucose-nutrient bath with a shallow water table so that the solution was sucked in by capillary rise. Thereafter, $4 \mathrm{~mL}$ of the glucose-nutrient solution were added from the top of the core with a pipette and allowed to infiltrate for 10min. Finally, the fully saturated soil cores were drained from macropores with low capillarity by placing the soil cores on a dry sand bed for $10 \mathrm{~min}$. After drainage, soil cores were placed into the Respicond for $48 \mathrm{~h}$ at $22^{\circ} \mathrm{C}$. The absorbed volume of glucose-nutrient solution was measured after the SIR approach via weight loss upon oven-drying as described above and accounting for the antecedent field moisture. The amount of absorbed glucose solution was different for every soil core and increases with decreasing field water content $\theta$ and increasing porosity $\phi$. However, for all soil cores glucose-C was provided in excess, i.e. the $\mathrm{CO}_{2}$ uptake capacity of the respirometer was exceeded with only a fraction of the mineralized C. The time, $t_{\text {exc }}$, until the capacity of the respirometer was exceeded (73mg $\mathrm{CO}_{2}$-C at the given $\mathrm{KOH}$ concentration), was determined for every soil core (Fig. 2). In addition, an empirical model for microbial growth kinetics (Wutzler et al., 2012) of the form

$$
p_{S I}(t)=A+B e^{\mu t}
$$

was fitted to the substrate-induced growth respiration stage of each time series using ModelMaker-3 software (SB Technology Ltd), where $p_{S I}$ is the substrate-induced respiration rate at time $t, A$ is the growth-independent $\mathrm{CO}_{2}$ release rate, $B$ is the growth-dependent $\mathrm{CO}_{2}$ release rate and $\mu$ is the microbial specific growth rate. The identification of a lag phase and initial substrate-induced respiration prior to growth $\left(\mathrm{p}_{0}=\mathrm{A}+\mathrm{B}\right)$ was obstructed by uncertain data during initial equilibration of the $\mathrm{CO}_{2}$ readings and had to be substituted by data extrapolation and a subjective definition of a lag phase as shown in Fig. 2. The active microbial fraction was determined as

$$
r_{0}=\frac{A M B}{T M B}=\frac{B(1-\lambda)}{A+B(1-\lambda)}
$$

where $A M B$ is the active microbial biomass participating in growth, $T M B$ is the total microbial biomass and $\lambda$ is a basic stoichiometric constant of 0.9 during unlimited growth (Akimenko et al., 1983) 


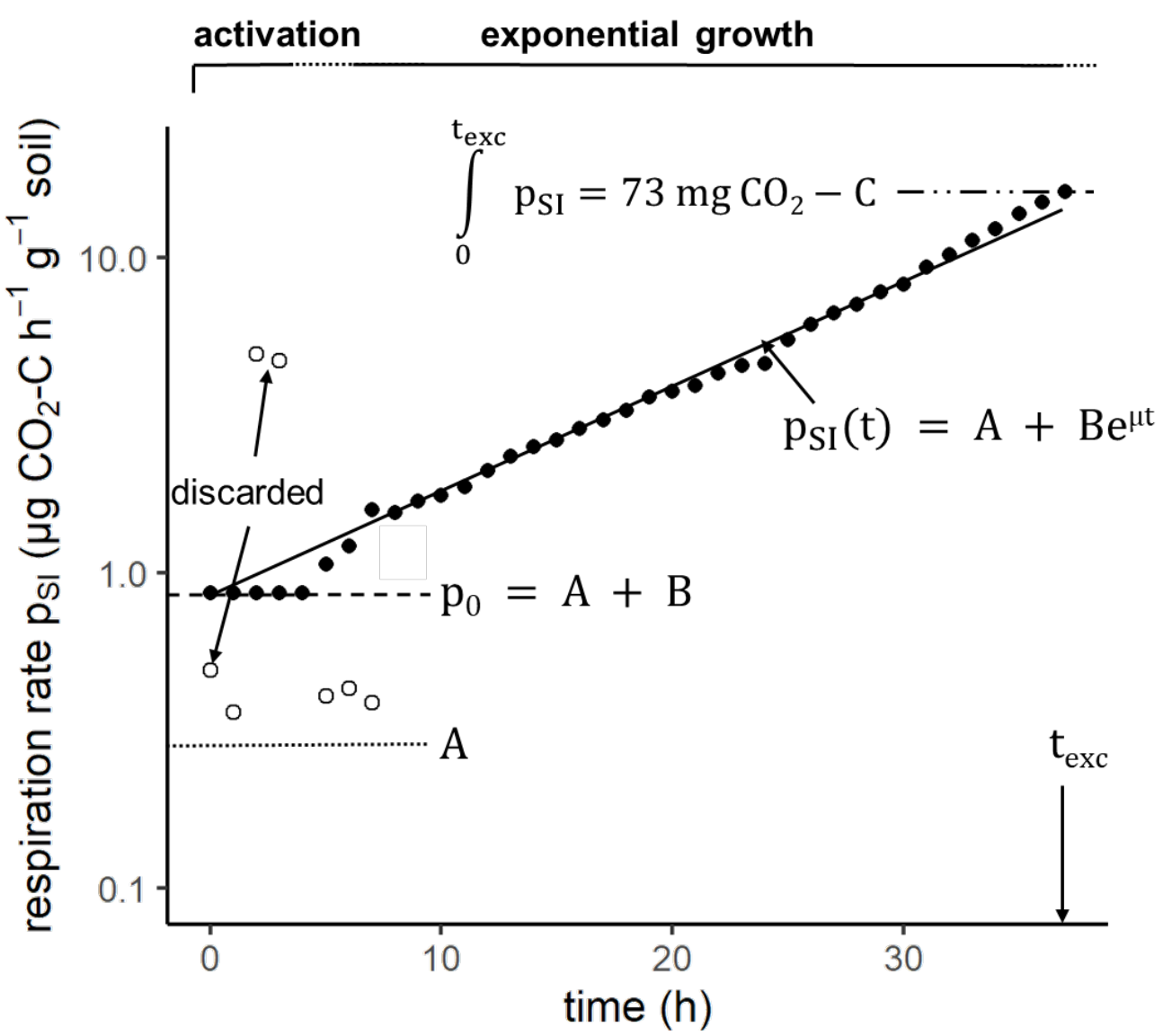

Figure 2: Example of a time series of $\mathrm{CO}_{2}$ release after glucose addition at $\mathrm{t}=-\mathbf{h}$ and first measurement at $\mathrm{t}=0 \mathrm{~h}$. The fluctuations in $\mathrm{CO}_{2}$ readings during the first hours (empty circles) were discarded and replaced by a constant substrate induced respiration rate $p_{0}$ during an initial lag phase. The parameters $\mu, A, B$ and $p_{0}$ are derived from a model fit, whereas $t_{\text {exc }}($ time until a total of 73mg $\mathrm{CO}_{2}-\mathrm{C}$ was respired) is directly calculated from the time series.

\subsection{Statistical Analysis}

Statistical analysis were performed with R (R Core Team, 2018) and figures were produced with package ggplot2 (Wickham, 2016). Normality of residuals and homogeneity of variances were tested with the Shapiro-Wilk test and Levene test at a level of $\mathrm{p}>0.05$, respectively. If these criteria were met, then one-factorial ANOVA followed Tukey HSD Postdoc test were carried out to identify significant differences between land use types at a level of $\mathrm{p}<0.05$ using the agricolae package (de Mendiburu, 2019). If the criteria were not met, then a non-parametric Kruskal-Wallis test was carried out at a level of $p<0.05$ with the same package. For simplicity, Pearson correlations between two variables are reported, irrespective whether normality in the residuals is fulfilled.

Partial least square regression was conducted in order to identify the amount of explained variability of a target variable $\left(p_{B}, t_{\text {exc }}\right.$ ) by a combination of explanatory variables. This was either done for the pooled data set (all land uses, $\mathrm{n}=60$ ) or individually for grassland soil cores $(\mathrm{IM}+\mathrm{EM}+\mathrm{EP} ; \mathrm{n}=30)$ and cropland soil cores $(\mathrm{CF}+\mathrm{OF}, \mathrm{n}=30)$. To do so, the target 
https://doi.org/10.5194/soil-2021-56

Preprint. Discussion started: 22 July 2021

(c) Author(s) 2021. CC BY 4.0 License.

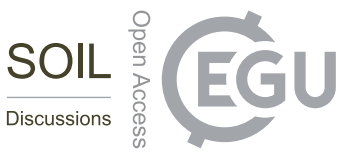

variables $\left(p_{B}, t_{\text {exc }}\right)$ and explanatory variables $\left(\rho, \theta / \phi, m_{r}, \phi_{\text {vis }}, a, b, \chi, \Gamma, d, \emptyset, \emptyset_{c}, p_{o}, \mu, r_{o}\right.$ (and $p_{B}$ for target variable $\left.t_{e x c}\right)$ ) were tested for normal distribution and if needed transformed to reach normal distributions and linear relationships of data (i.e., a logarithmic transformation or a logistic transformation $(\operatorname{logit}(\mathrm{x})=\log (\mathrm{x} /(1-\mathrm{x})))$.

205 There was collinearity between many variables of the present study, which excludes simple linear regressions to explore the variability of basal and substrate-induce respiration. Partial least square regression (PLSR) with Leave-One-Out Crossvalidated $\mathrm{R}^{2}$ allows for collinearity between variables and identifies the most important explanatory variables to predict the target variables. Permutation testing served to describe components that best explained $p_{B}$ and $t_{\text {exc }}$. Robust confidence intervals against deviations from normality were obtained from bootstrapping ( $\mathrm{R}$ package boot v. 1.3-24) (Davison and Hinkley, 1997;Canty and Ripley, 2019). The smoothed bootstrap was used by resampling from multivariate kernel density (R package kernelboot v. 0.1.7) (Wolodzko, 2020) as sample sizes were relatively small (60 in pooled and 30 in grouped data). The BCa bootstrap confidence interval of $95 \%$ of $\mathrm{R}^{2}$ was a measure to explain the variability in each response variable (Efron, 1987).

PLSR was repeated for a series of simplifications: a) complex model with all bulk, microstructural and microbial explanatory variables $\left(\theta / \phi\right.$ for $p_{B}$ and $\theta_{a}$ as well as $p_{B}$ for $\left.t_{e x c}\right)$; b) complex model including only bulk and microstructural properties ( $\mathrm{n}=11 p_{B}$ and $\mathrm{n}=12$ for $t_{\text {exc }}$, excluding $p_{o}, \mu, r_{o}$ ), c) a VIP model that includes only the most informative variables identified by PLSR ( $n=3-5$; composition varies between target variables and land use combinations), d) manually selected (pairs of) explanatory variables that serve as a base line reference ( $n=1-2$; choice depends on target variables).

\section{Results}

\subsection{Bulk properties}

At the early growing season (May) the young plants in both croplands (CF, OF) had transpired less water than the permanent vegetation cover in the three grasslands (IM, EM, EP) resulting in a significant difference in field water saturation (Table 1). In fact, the water contents in grassland were already close to the permanent wilting point at that soil depth $(\theta=0.09$ $\mathrm{mm}^{3} / \mathrm{mm}^{3}$ at $\mathrm{pF} 4.2$, personal communication by Max Koehne). The POM content ( $\left.>0.63 \mathrm{~mm}\right)$ mainly comprising roots and old plant residues incorporated by plowing was significantly lower in the farming plots (CF, OF) than in the grassland plots (IM, EM, EP) (Table 1). The TOC content followed the identical order, whereas C:N ratios did not differ significantly between any of the land uses (Table 1). Surprisingly, there was no difference in average bulk density between any of the land uses (Table 1). However, in farming plots the variability in bulk density was greater than in grasslands. This was triggered by randomized sampling locations within a plot that may either fall into areas loosened by plowing or areas compacted by traffic. The volumetric air content in the soil cores after the uptake of glucose solution was on average around 0.1 $\left(\mathrm{mm}^{3} / \mathrm{mm}^{3}\right)$ for all land uses. 
https://doi.org/10.5194/soil-2021-56

Preprint. Discussion started: 22 July 2021

(c) Author(s) 2021. CC BY 4.0 License.

Table 1: Arithmetic mean (mean) and standard deviation (sd) of variables for five different land uses grouped according to bulk properties, image-derived microstructure properties and respiration properties. TOC and C:N are based on plot averages, all other directly at the soil core level.; Small letters represent significant differences among treatments $(p<0.05)$. TOC Total organic carbon, POM Particulate Organic Matter.

\begin{tabular}{|c|c|c|c|c|c|c|c|c|c|c|c|}
\hline \multirow[b]{2}{*}{ property } & \multirow[b]{2}{*}{ unit } & \multicolumn{2}{|c|}{$\begin{array}{l}\text { conventional } \\
\text { farming CF }\end{array}$} & \multicolumn{2}{|c|}{$\begin{array}{l}\text { organic farming } \\
\text { OF }\end{array}$} & \multicolumn{2}{|c|}{$\begin{array}{l}\text { intensive } \\
\text { meadow IM }\end{array}$} & \multicolumn{2}{|c|}{$\begin{array}{l}\text { extensive } \\
\text { meadow EM }\end{array}$} & \multicolumn{2}{|c|}{$\begin{array}{l}\text { extensive } \\
\text { pasture EP }\end{array}$} \\
\hline & & mean & sd & mean & sd & mean & sd & mean & sd & mean & sd \\
\hline bulk density $\rho$ & $\mathrm{g} \mathrm{cm}^{-3}$ & 1.41 & 0.09 & 1.41 & 0.10 & 1.41 & 0.04 & 1.42 & 0.07 & 1.38 & 0.07 \\
\hline field water saturation $\theta / \phi$ & $\mathrm{mm}^{3} \mathrm{~mm}^{-3}$ & $0.50 \mathrm{a}$ & 0.10 & $0.47 a$ & 0.11 & $0.29 \mathrm{~b}$ & 0.06 & $0.26 \mathrm{~b}$ & 0.05 & $0.30 \mathrm{~b}$ & 0.10 \\
\hline SIR air content $\theta_{a}$ & $\mathrm{~mm}^{3} / \mathrm{mm}^{3}$ & $0.09 \mathrm{~b}$ & 0.03 & $0.10 \mathrm{ab}$ & 0.02 & $0.11 \mathrm{ab}$ & 0.01 & $0.11 \mathrm{ab}$ & 0.02 & $0.12 \mathrm{a}$ & 0.03 \\
\hline TOC content & $\mathrm{mg} \mathrm{g}^{-1}$ & $19.1 b$ & 0.8 & $19.0 b$ & 0.3 & $20.5 a b$ & 0.6 & $21.3 a$ & 1.0 & $21.3 a$ & 1.4 \\
\hline $\mathrm{C}: \mathrm{N}$ ratio & - & 13.6 & 0.6 & 13.3 & 1.1 & 13.4 & 0.5 & 13.9 & 0.8 & 13.4 & 0.2 \\
\hline POM content $m_{r}$ & $\mathrm{mg} \mathrm{g}^{-3}$ & $1.00 \mathrm{~b}$ & 0.46 & $1.19 \mathrm{~b}$ & 0.51 & $1.76 \mathrm{a}$ & 0.63 & $2.21 \mathrm{a}$ & 0.98 & $2.18 \mathrm{a}$ & 0.67 \\
\hline visible porosity $\phi_{v i s}$ & $\mathrm{~mm}^{3} \mathrm{~mm}^{-3}$ & 0.13 & 0.07 & 0.14 & 0.05 & 0.15 & 0.01 & 0.16 & 0.03 & 0.16 & 0.03 \\
\hline surface area density $a$ & $\mathrm{~mm}^{2} \mathrm{~mm}^{-3}$ & 2.30 & 0.79 & 2.58 & 0.84 & 2.45 & 0.36 & 2.37 & 0.23 & 2.51 & 0.38 \\
\hline mean breadth density $b$ & $\mathrm{~mm} \mathrm{~mm}^{-3}$ & 1.59 & 0.46 & 1.74 & 0.39 & 1.65 & 0.44 & 1.37 & 0.25 & 1.56 & 0.33 \\
\hline Euler number density $\chi$ & $\mathrm{mm}^{-3}$ & 1.31 & 3.21 & 0.33 & 3.39 & 1.37 & 0.89 & 1.47 & 0.81 & 1.34 & 1.06 \\
\hline connection probability $\Gamma$ & - & $0.73 \mathrm{c}$ & 0.24 & $0.79 \mathrm{bc}$ & 0.23 & $0.92 \mathrm{ab}$ & 0.02 & $0.92 \mathbf{a}$ & 0.03 & $0.92 \mathbf{a}$ & 0.02 \\
\hline mean pore diameter $\varnothing$ & $\mathrm{mm}$ & $0.21 \mathrm{~b}$ & 0.05 & $0.21 \mathrm{~b}$ & 0.03 & $0.36 \mathbf{a}$ & 0.25 & $0.37 \mathrm{a}$ & 0.14 & $0.40 \mathrm{a}$ & 0.16 \\
\hline critical pore diameter $\emptyset_{c}$ & $\mathrm{~mm}$ & $0.28 \mathrm{c}$ & 0.10 & $0.41 \mathrm{~b}$ & 0.06 & $0.51 \mathrm{~b}$ & 0.21 & $0.82 \mathrm{a}$ & 0.57 & $0.74 \mathrm{a}$ & 0.37 \\
\hline mean pore distance $d$ & $\mathrm{~mm}$ & 0.18 & 0.04 & 0.17 & 0.04 & 0.16 & 0.02 & 0.17 & 0.02 & 0.16 & 0.02 \\
\hline POM volume density $v_{r}$ & $\mathrm{~mm}^{3} \mathrm{~cm}^{-3}$ & $10.7 \mathrm{~b}$ & 3.2 & $15.6 \mathrm{~b}$ & 5.6 & $21.2 \mathrm{a}$ & 5.9 & $21.9 \mathrm{a}$ & 7.6 & $21.5 \mathrm{a}$ & 4.0 \\
\hline basal respiration $p_{B}$ & $\mu \mathrm{g} \mathrm{CO}_{2}-\mathrm{Cg}^{-1} \mathrm{~h}^{-1} 1$ & $0.32 \mathrm{c}$ & 0.14 & $0.36 \mathrm{c}$ & 0.09 & 0.42 bc & 0.15 & $0.56 \mathrm{~b}$ & 0.33 & $0.70 \mathrm{a}$ & 0.23 \\
\hline growth independent release $A$ & $\mu \mathrm{g} \mathrm{CO}_{2}-\mathrm{Cg}^{-1} h^{-1}$ & $0.61 \mathbf{b}$ & 0.35 & $0.56 \mathbf{b}$ & 0.42 & $1.73 \mathrm{a}$ & 1.25 & 1.99 a & 1.34 & $2.11 \mathrm{a}$ & 1.44 \\
\hline growth dependent release $B$ & $\mu \mathrm{g} \mathrm{CO}_{2}-\mathrm{Cg}^{-1} h^{-1}$ & $0.36 \mathbf{b}$ & 0.29 & $0.50 \mathrm{~b}$ & 0.38 & $1.15 \mathrm{a}$ & 0.55 & $1.10 \mathrm{a}$ & 0.78 & $1.43 \mathrm{a}$ & 1.20 \\
\hline substrate induced release $p_{0}$ & $\mu \mathrm{g} \mathrm{CO}_{2}-\mathrm{Cg}^{-1} \mathrm{~h}^{-1}$ & $0.97 \mathrm{~b}$ & 0.36 & $1.06 \mathrm{~b}$ & 0.55 & $2.88 \mathrm{a}$ & 1.13 & $3.09 \mathrm{a}$ & 0.85 & $3.54 \mathrm{a}$ & 1.30 \\
\hline growth rate $\mu$ & h-1 & 0.10 & 0.03 & 0.09 & 0.02 & 0.09 & 0.03 & 0.10 & 0.05 & 0.10 & 0.03 \\
\hline total microbial biomass $T M B$ & $\mu g$ C g-1 & $86 \mathrm{~b}$ & 46 & $90 \mathrm{~b}$ & 65 & 299 a & 212 & $276 a$ & 151 & $312 a$ & 120 \\
\hline active microbial biomass $A M B$ & $\mu g$ Cg-1 & $6.0 \mathrm{c}$ & 6.3 & $8.7 \mathrm{bc}$ & 8.1 & 20.9 a & 14.5 & $20.2 \mathrm{ab}$ & 18.6 & $19.5 \mathrm{ab}$ & 19.2 \\
\hline active fraction $r_{0}$ & - & 0.09 & 0.12 & 0.14 & 0.20 & 0.14 & 0.16 & 0.13 & 0.19 & 0.09 & 0.09 \\
\hline time of capacity excess $t_{\text {exc }}$ & $\mathrm{h}$ & 39.5 a & 3.0 & 39.4 a & 4.5 & $26.7 \mathrm{~b}$ & 2.5 & $26.1 \mathrm{~b}$ & 2.2 & $24.3 \mathrm{~b}$ & 4.6 \\
\hline
\end{tabular}

\subsection{Microstructure properties}

The visible microstructure in the topsoil differed vastly between land uses but also among soil cores of the same land use. The 2D slices of selected X-ray CT images in Fig. 3f are not meant to be representative for the land use, but exemplary to 240 show the entire variability in size and volume fraction of pores as well as the volume fraction of particulate organic matter. The visible porosity does not differ across land uses but has a much higher variability in farming plots (Fig. 3a, Table 1). Visible porosity $\left(>0.03 \mathrm{~mm}\right.$ ) and bulk density were strongly correlated (Fig. $3 b, \mathrm{R}^{2}=0.74, \mathrm{p}<0.001$ ), since it is mainly the macroporosity that is affected by soil management. There was a number of other pore metrics like surface area, mean 
https://doi.org/10.5194/soil-2021-56

Preprint. Discussion started: 22 July 2021

(c) Author(s) 2021. CC BY 4.0 License.

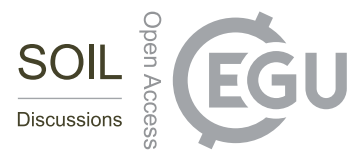

breadth, Euler number and mean pore distance that also did not differ between land uses (Table 1). The mean pore diameter

was significantly larger in grassland than in farming plots (Fig. 3c, Table 1), because a certain fraction of the pore space was contributed by large biopores including taproot channels and earthworm burrows, which are periodically destroyed by plowing in farming plots. Likewise, the critical pore diameter was significantly larger in EP and EM than in OF and even lower in CF. Interestingly, the critical pore diameter in IM was more similar to that in OF, indicating that biopores in intensive meadow are less often continuous from top to bottom. Following the pattern of the POM content $\left(\mathrm{m}_{\mathrm{r}}\right)$, the POM volume was significantly higher in grassland than in cropland soil (Fig. 3d, Table 1). The correlation between image-derived POM volume and POM content determined by wet sieving (Fig. 3e, $\mathrm{R}^{2}=0.53$ ) was somewhat lower than correlation for independently determined proxies for porosity discussed above. This is likely caused by incomplete POM detection by both methods and the differences in the lower size cut-off (downscaled image resolution of $0.06 \mathrm{~mm}$ vs $0.63 \mathrm{~mm}$ mesh size of sieve) as well as between mass density and volume density..
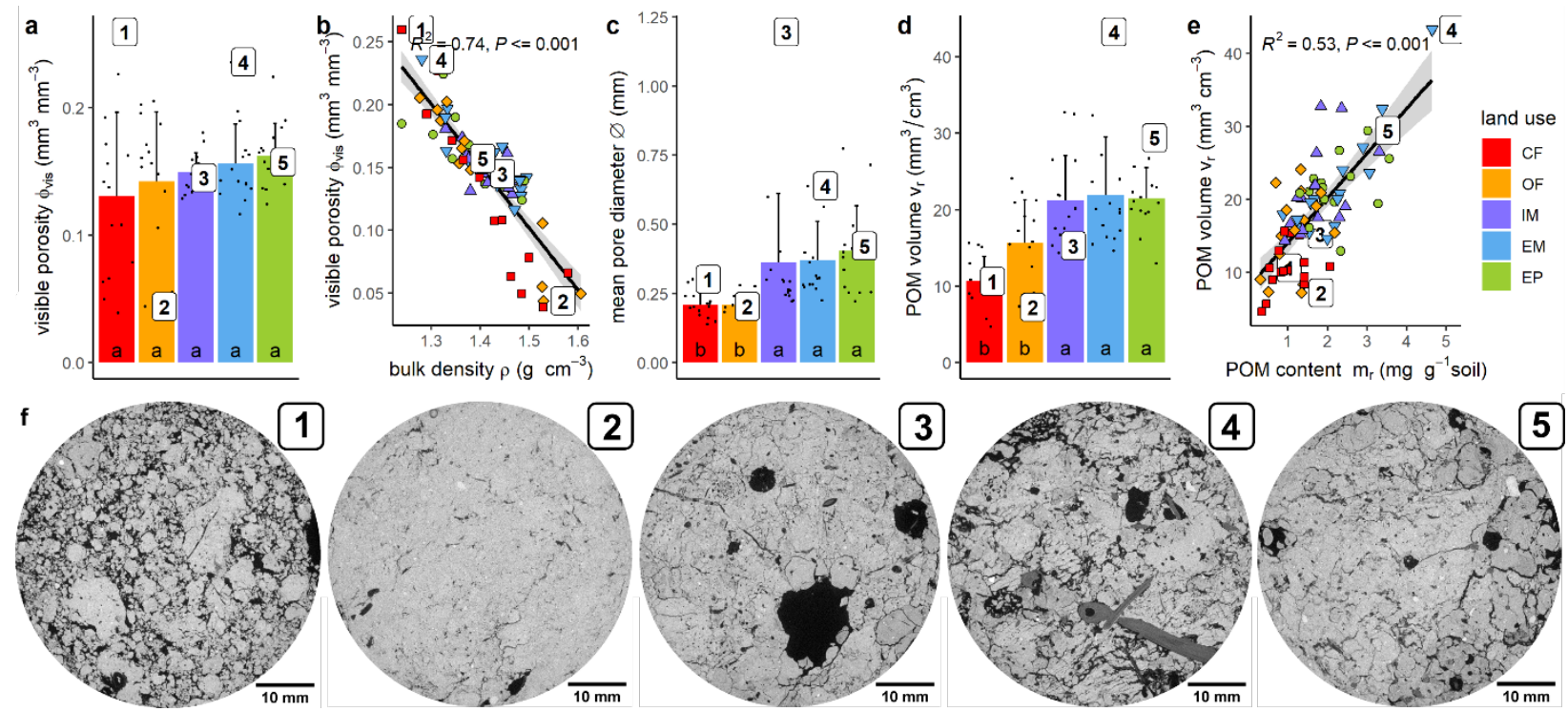

Figure 3: Selected microstructure properties (a, c, d) and relation to selected bulk properties (b, e) for different land uses. Columns and error bars represented mean and standard deviation at the plot level $(n=5)$, whereas dots represent individual soil cores. Numbered dots in subfigures a-e correspond to the five selected X-ray CT samples, for which 2D sections are shown below. Different letters in barplots $(a, c, d)$ indicate significant differences $(\mathbf{p}<0.05)$ between land use types.

\subsection{Respiration properties}

Basal respiration at field moisture was highest in extensive pasture and lowest in both farming plots with intermediate rates for both meadows (Fig. 4a,Table 1). Basal respiration correlated strongly with POM content (Fig. 4b, $\mathrm{R}^{2}=0.53, \mathrm{p}<0.001$ ) and only slightly less with POM volume density $\left(\mathrm{R}^{2}=0.35\right.$, not shown). Surprisingly, basal respiration was completely independent of initial water saturation when pooled across land uses, even though the entire range between supposedly critical dryness and optimal conditions was covered (Fig. 4c). Furthermore, basal respiration was independent of visible porosity (Fig. 4d) 

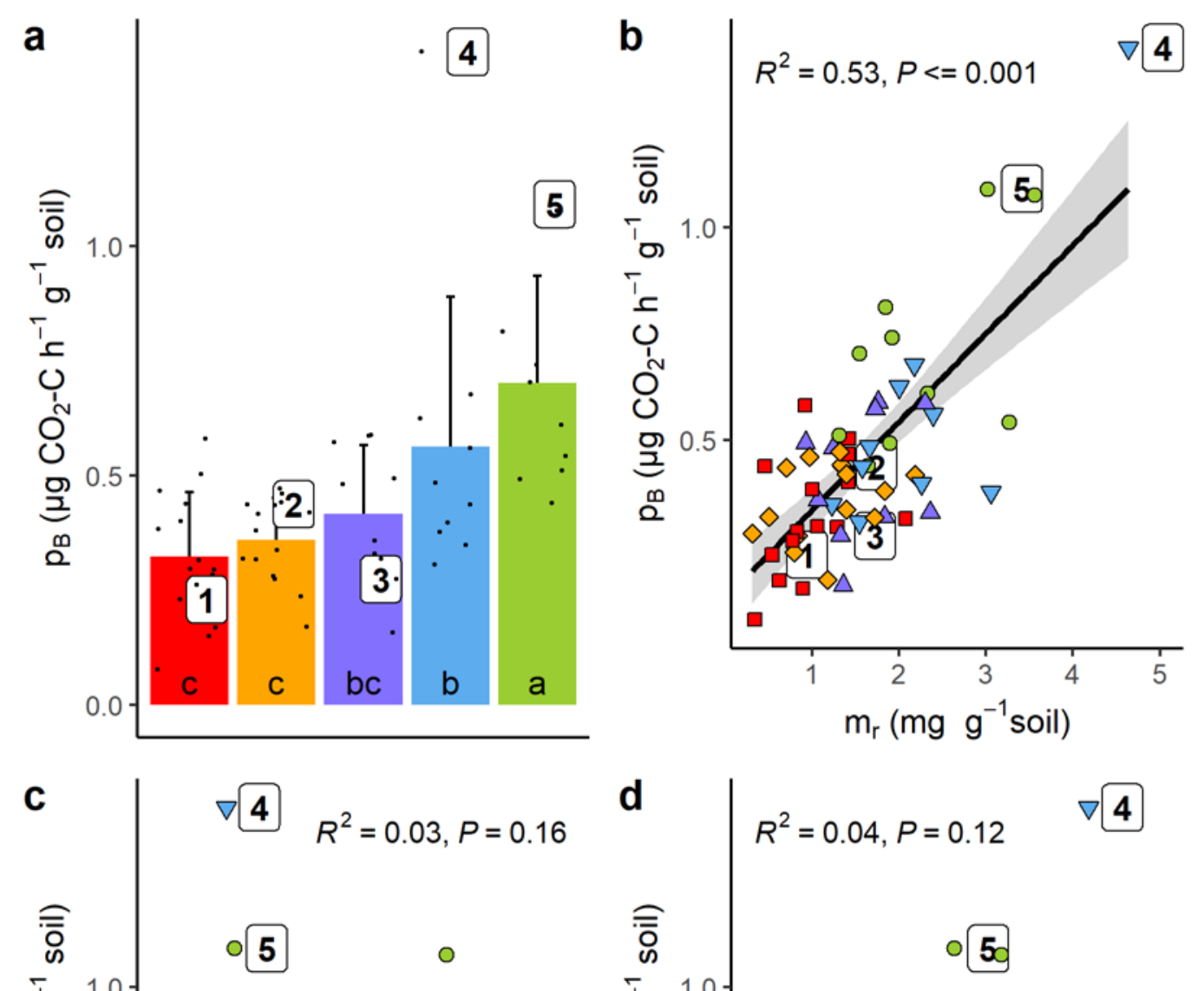

land use

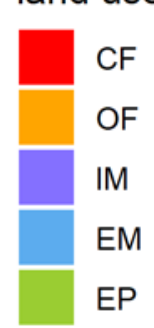

Figure 4: a) Basal respiration as a function of a) land use, b) POM mass $\left(m_{r}\right)$, c) field water saturation $(\theta / \phi)$ and d) visible porosity $(>30 \mu \mathrm{m})\left(\phi_{\text {vis }}\right)$. The numbered dots correspond to the samples depicted in Fig. 3f. Different letters in the barplot (subfigure a) indicate significant differences $(p<0.05)$ between land use types.

Substrate-induced respiration in the first hours after glucose addition $\left(p_{0}=A+B\right)$ was up to 3.5 times higher in all grasslands than in both farming treatments (Fig. 5a). The correlation between basal respiration and initial substrate-induced 
https://doi.org/10.5194/soil-2021-56

Preprint. Discussion started: 22 July 2021

(c) Author(s) 2021. CC BY 4.0 License.

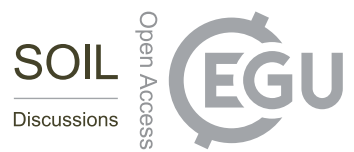

respiration prior to growth was highly significant (Fig. 5b, $\mathrm{R}^{2}=0.59, \mathrm{p}<0.001$ ) and amounted to a six-fold increase in respiration rates by glucose addition, which is in agreement with previous incubation studies (Wardle and Ghani, 1995; Hund

and Schenk, 1994) and indicated limitation of microbial activity in all collected soils due to substrate deficiency (Blagodatskaya and Kuzyakov, 2013). The correlation deteriorated slightly $\left(\mathrm{R}^{2}=0.31, \mathrm{p}<0.001\right)$, when those samples with exceptionally high $p_{B}$ due to high root biomass and those samples with exceptionally low $p_{0}$ that might have been caused by insufficiently precise estimation of lag time were disregarded.
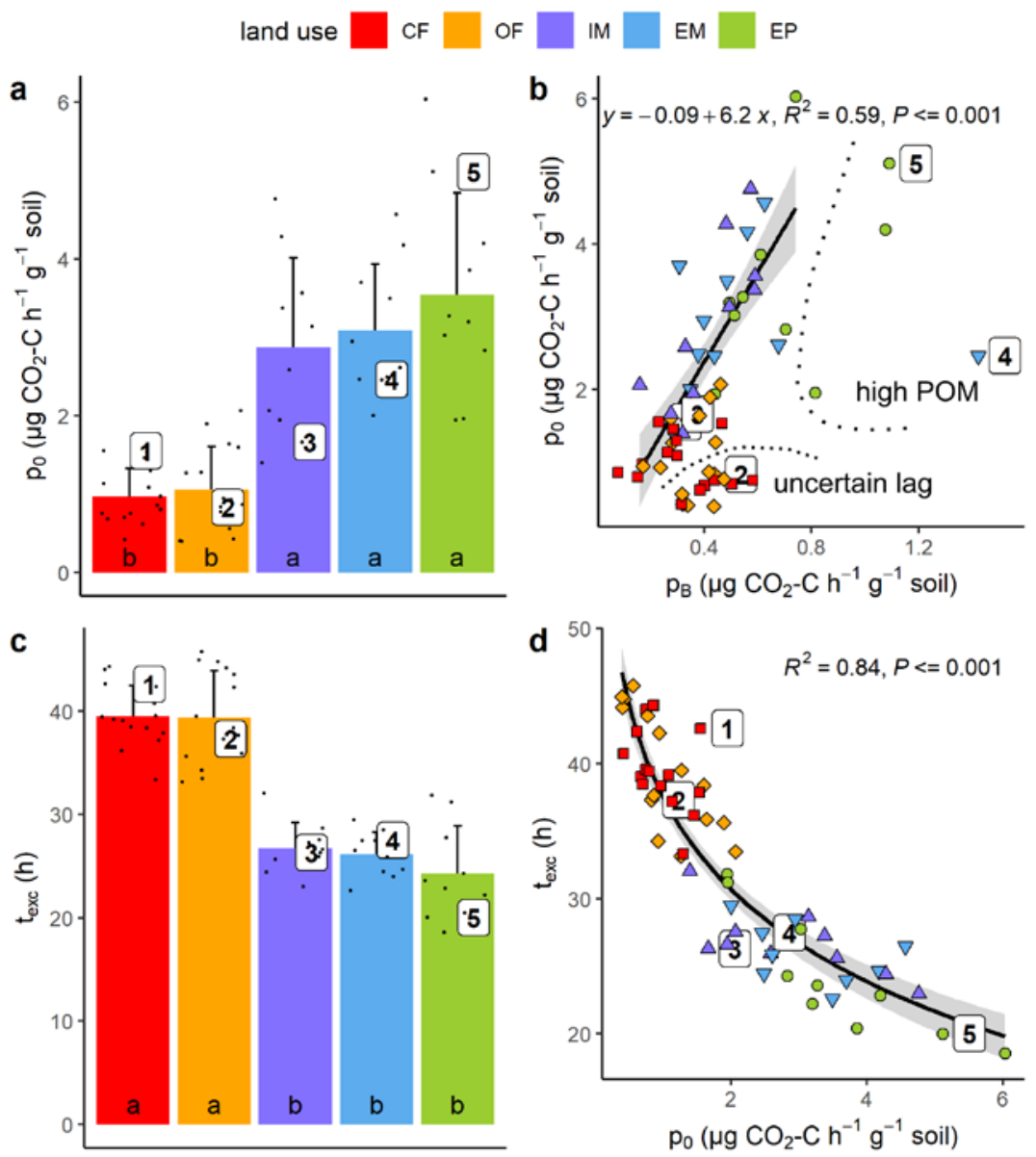

Figure 5: Initial substrate-induced respiration prior to growth $\left(p_{o}\right)$ as a function of (a) land use and (b) basal respiration $\left(p_{B}\right)$ as well as time until capacity excess of the respirometer $\left(t_{\text {exc }}\right)$ as a function of (c) land use and (d) substrate induced respiration $\left(p_{o}\right)$. High POM and uncertain lag in (b) indicate those samples that have been excluded from regression analysis. Different letters in barplots $(a, c)$ indicate significant differences $(p<0.05)$ between land use types.

Due to higher initial microbial activity, the added glucose was consumed much faster in grassland soils and reached the $\mathrm{CO}_{2}$ uptake capacity of the respirometer much sooner as compared to cropland soils (Fig. 5c, Fig. S 1). The logarithm of this time of capacity excess, $t_{e x c}$, was tightly linked to $p_{0}$ (Fig. $5 \mathrm{~d}, \mathrm{R}^{2}=0.84, \mathrm{p}<0.001$ ) and to a similar extend to total microbial 
https://doi.org/10.5194/soil-2021-56

Preprint. Discussion started: 22 July 2021

(c) Author(s) 2021. CC BY 4.0 License.

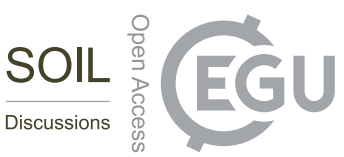

biomass $T M B$ (not shown, $\mathrm{R}^{2}=0.60, \mathrm{p}<0.001$ ), which is coupled with $p_{0}$ through eq. (2). Only two parameters of the model (eq. 1) that was fitted to the exponential increase in $\mathrm{CO}_{2}$ release were different between grasslands and croplands (Table 1).

The growth-independent respiration rate $A$ and the growth-dependent respiration rate $B$ (just as its sum $p_{0}$ ) were both significantly smaller in cropland soils, which accounts for the fact that initial $\mathrm{CO}_{2}$ release rate directly after glucose addition were lower. The microbial growth constant $\mu$ did not differ between land uses. Following the pattern of the total biomass, the active microbial biomass was higher in grasslands than in croplands. The variability in the active fraction of microbial biomass was, however, too high among replicates to evoke significant differences between land uses.

In summary, six years of different land use induced significant changes in soil properties that are expected to change slowly (TOC content), while others remained unchanged (bulk density, C:N ratio). In addition, some land uses differed in soil properties that are expected to follow a seasonal pattern (e.g. POM volume, pore diameter) induced by different vegetation cover during a growing season and presence or absence of tillage. Finally, plots from different land uses also varied in terms of spatial heterogeneity. The combination of all these effects constitute a comprehensive dataset of soil structures for testing which minimum set of bulk and microstructure properties is required to predict soil respiration across a range microbial activities differing by at least one order of magnitude.

\subsection{Prediction of respiration properties}

Many microstructural properties correlate significantly among each other and with bulk properties (complete correlation matrix in Fig. S 2). Likewise, many respiration properties correlate among each other (partly by definition and accounted for by only considering the independent variables $p_{B}, p_{0}, r_{0}$ and $\mu$ in the following) and with microstructural and bulk properties

(Fig. S 2). This collinearity among microstructural, bulk and microbial parameters is directly accounted for by partial least squares regression (PLSR).

Simple regressions of basal respiration with selected bulk or microstructure properties in the previous section already highlighted the importance of POM content, $m_{r}$, for explaining the variability in basal respiration $p_{B}\left(\mathrm{R}^{2}=0.53, \mathrm{p}<0.001\right)$.

310 The predictive power of $m_{r}$ on $p_{B}$ is reduced to a median $\mathrm{R}^{2}$ of 0.34 by PLSR with data normalization and boot strapping. The predictive power of the complex model for basal respiration among all land uses only increased to $\mathrm{R}^{2}=0.43$ when all abiotic and microbial variables were considered as explanatory variables (Fig. 7a), which can mainly be attributed to a higher degree of explained variability in grassland soils (from $\mathrm{R}^{2}=0.27$ to $\mathrm{R}^{2}=0.53$ ). This gain in predictive power of the complex model can be attributed to the added information content of microbial parameters as its omission (all- $\left.p_{0}-r_{0}-\mu\right)$ results in a

315 lower, almost identical predictive power like the simplest model with $m_{r}$ only. Indeed, the VIP model for grasslands include $p_{o}, m_{r}, \theta / \phi, \rho$, and $\mu$ in descending order of importance. In general, the explained variability was higher for grasslands and very poor for cropland soils. The explained variability is increased by 0.1-0.2 in comparison to the bootstrapping median and reaches $\mathrm{R}^{2}>0.60$, if supposed outlier samples are discarded by the Leave-one-out procedure. The surprisingly low information content of field water saturation is confirmed. The collinearity of many explanatory variables is indicated by similar directions in Fig. 7b. Only those parameters with long vectors at an angle sufficiently different from $0^{\circ}$ or $180^{\circ}$ can 
https://doi.org/10.5194/soil-2021-56

Preprint. Discussion started: 22 July 2021

(c) Author(s) 2021. CC BY 4.0 License.

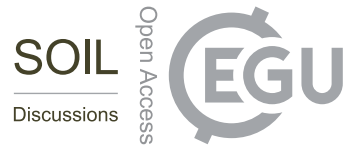

provide meaningful, complementary information. The congruency of the direction of $m_{r}$ with the scatter of grassland soils reflects the higher predictive power as compared to cropland soils.
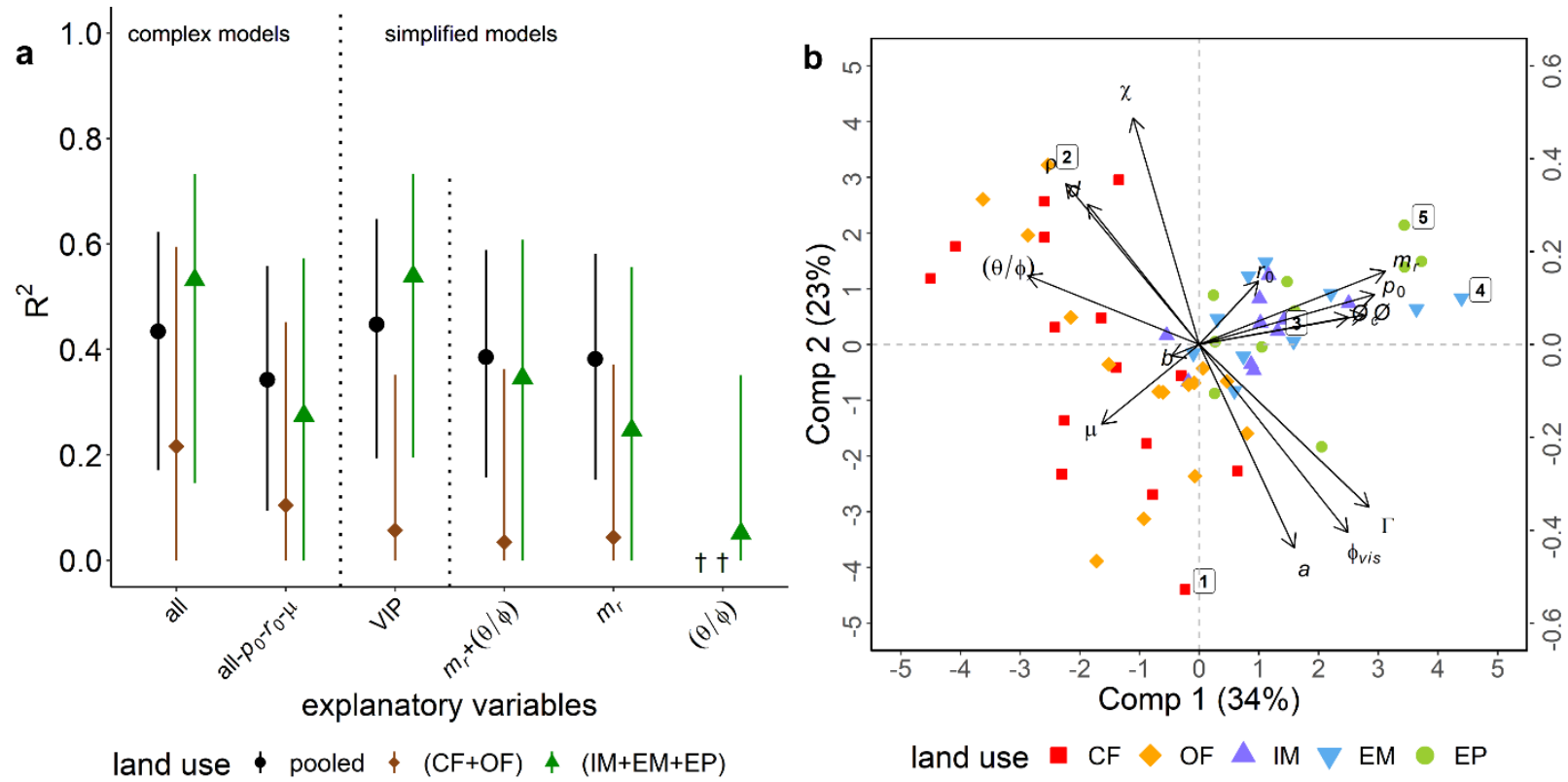

Figure 6: a) Explained variability $\left(\mathrm{R}^{2}\right)$ of basal respiration, $p_{b}$, by different combinations of explanatory variables for all land uses (pooled) or only farming (CF+OF) and grassland (IM+EM+EP), respectively. VIP models include the variables of importance to predict $p_{b}$ (Please refer to the text for more information). $†$ no variability explained. b) Biplot with scores of individual samples from different land uses in the first principal components $\left(1^{\text {st }} x y\right.$-axis $)$ and loadings $\left(2^{\text {nd }} y\right.$-axis $)$ showing the influence of explanatory variables on components. The numbered labels (1-5) correspond to samples depicted in Fig. 3. 


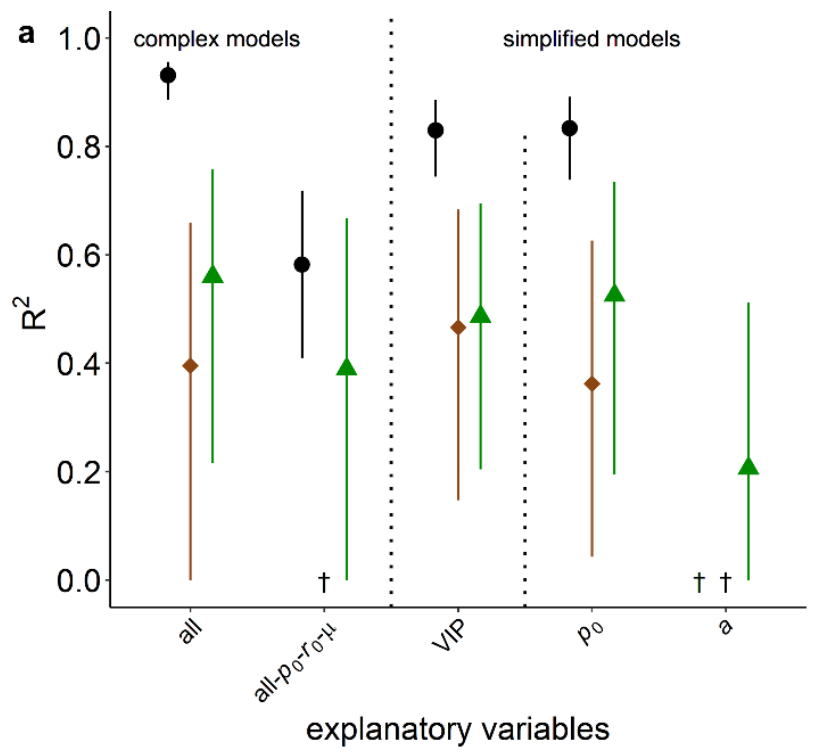

land use pooled $\$(\mathrm{CF}+\mathrm{OF})$ \& $(\mathrm{IM}+\mathrm{EM}+\mathrm{EP})$

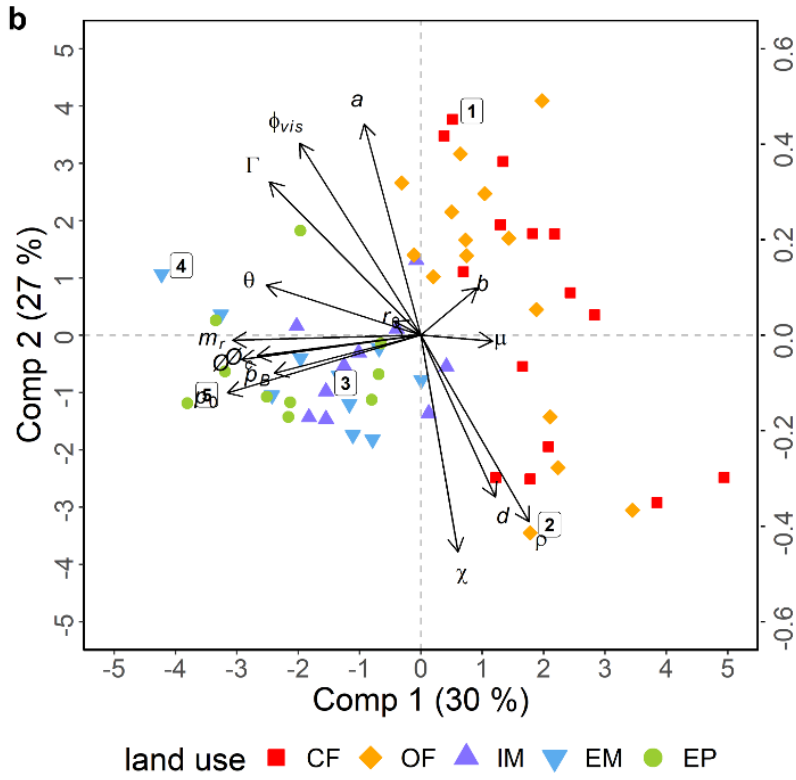

Figure 7: a) Explained variability $\left(\mathrm{R}^{2}\right)$ of time of capacity excess, $t_{\text {exc }}$, during substrate induced respiration $\left(\mathrm{t}_{\mathrm{ave}}\right)$ by different combinations of explanatory variables for all land uses (pooled) or only farming (CF+OF) and grassland (IM+EM+EP), respectively. VIP models include the variables of importance to predict $t_{\text {ave }}$ (Please refer to the text for more information). $\dagger$ no variability explained. b) Biplot with scores of individual samples from different land uses in the first principal components $\left(1^{\text {st }} x y-\right.$ axis) and loadings $\left(2^{\text {nd }}\right.$ y-axis) showing the influence of explanatory variables on components. The numbered labels (1-5) correspond to samples depicted in Fig. 3.

The explained variability observed for the time of capacity excess, $t_{\text {exc }}$, after glucose addition is excellent for the full complexity model in the pooled data set $\left(\mathrm{R}^{2}=0.93\right.$, Fig. $\left.8 \mathrm{a}\right)$. The model is better suited to explain the differences between grassland and cropland soils than to explain the variability within the two groups. A reduction in model complexity to the VIP model and even $p_{0}$ as the only explanatory variable does hardly reduce predictive power. The omission of microbial parameters (all- $p_{0}-r_{0}-\mu$ ) reduces the explained variability in $t_{\text {exc }}$ of the pooled land uses to $\mathrm{R}^{2}=0.58$, mainly because bulk and microstructure variables can only explain the variability between grassland and cropland, and to a lower degree within grasslands, but not the variability in $t_{\text {exc }}$ among cropland soils as shown exemplarily for pore surface area $a$. Differences in metabolic pathways due to different aeration of soil cores, e.g. between loosened and compacted soil in croplands, can be ruled out as unaccounted source of variability, as these should have been clearly reflected in image-derived pore metrics like $\phi_{v i s}$ and $\Gamma$ and even more directly in air content $\theta_{a}$. In fact, $\theta_{a}$ after glucose addition correlated less with the speed of glucose mineralization $t_{\text {exc }}$ than $\theta / \phi$ in the field prior to glucose addition did (Fig. S 2). The different clustering of grassland and cropland soils in the corresponding biplot (Fig. 8b) reflects again the better congruency of $p_{0}$ with the scatter among grassland samples than with the scatter among cropland samples.

\section{Discussion}

\subsection{Land use impact on soil properties and respiration}


https://doi.org/10.5194/soil-2021-56

Preprint. Discussion started: 22 July 2021

(c) Author(s) 2021. CC BY 4.0 License.

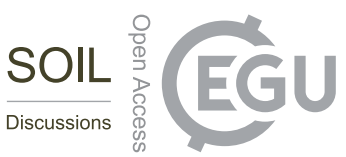

Land use specific soil management affected soil structural properties, which showed particular large differences between grasslands and croplands. The lack of tillage in grasslands promotes the continuity of large biopores formed by taproots and earthworms, which was reflected in larger average and critical macropore diameters $\left(\varnothing, \emptyset_{c}\right.$, Table 1) (Schlüter et al., 2020). At the same time, the continuous cover with perennial vegetation and the lack of mechanical disturbance by tillage promoted the built-up of soil organic C in grassland topsoils (TOC, Table 1) (Poeplau and Don, 2013). Differences between grassland and cropland soil in terms of plant residues, root biomass as well as water saturation in the topsoil $\left(m_{r}, v_{r}, \theta / \phi\right.$, Table 1$)$ were likely related to the fact that crops were still in an early growth stage, and had not established a dense root network, which limits water uptake and transpiration at the time of sampling in May. This discrepancy would have been smaller for winter crops (Thorup-Kristensen et al., 2009) and are likely to vanish during a growing season (Schlüter et al., 2013;Perkons et al., 2014). A somewhat surprising result was the equal average bulk densities in all land uses, as tillage is known to reduce bulk density in topsoils (Strudley et al., 2008;Palm et al., 2014). A bulk density of $1.4 \mathrm{~g} \mathrm{~cm}^{-3}$ is rather typical for grasslands at the Bad Lauchstädt site (Altermann et al., 2005), whereas previously reported bulk densities of tilled soils in other field trials on site tend to be higher, in the range of 1.46-1.62 $\mathrm{g} \mathrm{cm}^{-3}$ (Eden et al., 2012) or lower, in the range of 1.12-1.27 $\mathrm{g} \mathrm{cm}^{-3}$ (personal communication, Max Koehne) depending on soil management and sampling time. Bulk densities do not only undergo a seasonal variation, but are also spatially quite variable depending on whether or not remnants of old or recent wheel tracks are sampled (Roger-Estrade et al., 2004).

There were also subtle, but consistent differences within cropland and grassland treatments. Organic farming had significantly larger critical pore diameters $\left(\emptyset_{c}\right.$, ) and tended to have slightly higher POM volume densities $\left(v_{r}, \mathrm{p}=0.106\right)$, presumably due to the more prominent presence of large crop residues from the previous growing seasons. Indeed OF had a 7.5\% higher straw production compared to CF in 2019 (data from continuous GCEF monitoring program). This however, did not entail significant differences in carbon mineralization under ambient conditions. In grasslands, basal respiration differed significantly in the order IM $<$ EM $<$ EP (Table 1), even though there were no clear differences in bulk properties, microstructural properties or microbial parameters derived from subsequent substrate-induced respiration between the two meadows and the pasture. The lower basal respiration of IM soil, compared to EM and EP soils, is likely caused by the lower root biomass, represented by the lower POM content in our study. However, none of the available data sets could explain the observed differences between EM and EP. Thus, this difference is possibly caused by the microbial community structure and its trait composition which is known to affect C mineralization rates (Guo et al., 2020;Nazaries et al., 2015;Auffret et al., 2016)

\subsection{Controlling factors of respiration}

380 The combined impact of bulk density, field water saturation and POM contents resulted in a huge variability of soil heterotrophic respiration in $100 \mathrm{~cm}^{3}$ of intact topsoil at field moisture totaling more than one order of magnitude (0.08-1.42 $\mu \mathrm{g} \mathrm{CO}_{2}-\mathrm{C} \mathrm{h}^{-1} \mathrm{~g}^{-1}$ soil). This basal respiration was best described by the POM content of the sample. The POM contents also differed by more than one order of magnitude (0.3-4.6 $\mathrm{mg} \mathrm{g}^{-1}$ soil) because 1) in croplands roots were still young and POM 
https://doi.org/10.5194/soil-2021-56

Preprint. Discussion started: 22 July 2021

(c) Author(s) 2021. CC BY 4.0 License.

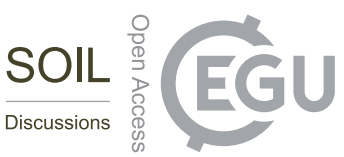

predominantly contributed by plant residues from the last growing season and 2) due to spatial variability in root length density especially within grassland plots. Macroporosity $\left(\phi_{v i s}\right)$ had no impact on basal respiration. This apparently contradicts previous studies, which showed that soil compaction reduced soil respiration (Liebig et al., 1995). A subsequent study revealed that this reduction of carbon mineralization was particularly strong in loamy sand soil when bulk densities were higher than $1.5 \mathrm{~g} \mathrm{~cm}^{-3}$ and plant residues were present at the same time, whereas unamended soil or less compacted soil showed less of a response (De Neve and Hofman, 2000). In the present study those soil cores with high POM content had low bulk density and vice versa, implying countervailing environmental impacts on basal respiration which may have caused its indifference to macroporosity $\left(\phi_{v i s}\right)$. Surprisingly, water saturation had no measurable effect on carbon mineralization, even though it was very low $(\theta / \phi<0.2)$ in some grassland cores. It is likely that the root material, which started to decay after sampling retained enough water by natural absorbance (Kravchenko et al., 2017) and released easily degradable substrates through cell lysis after sampling to act as microbial hotspots despite the onset of substrate limitation in an otherwise dry soil. In general, those cores that were driest, also had the highest POM volume $\left(\mathrm{R}^{2}=0.39, \mathrm{p}<0.001\right)$, which counterbalanced the substrate limitation effect in bulk soil. In none of the soil cores the initial water saturation was high enough to induce a deficiency of soil aeration. A large part of air-filled porosity was not even resolved at a voxel size of $30 \mu \mathrm{m}$. That is why visible macroporosity $\left(\phi_{v i s}\right)$ and all other pore metrics that are highly correlated with $\phi_{v i s}$ (Fig. S 2) do not add any substantial predictive power for basal respiration, which is in accordance with previous findings (Juarez et al., 400 2013). In addition, since image-derived $\phi_{v i s}$ and $v_{r}$ are highly correlated with $\rho$ and $m_{r}$ (Fig. 3,Fig. S 2) they can be substituted by simple bulk properties without loss in predictive power. Our findings indicate that carbon mineralization in well-aerated topsoils that contain fresh POM is biologically driven and mainly governed by carbon availability (Kuzyakov et al., 2009) and less by abiotic processes (diffusion, desorption, chemical reactions) as proposed by the regulatory gate hypothesis (Kemmitt et al., 2008).

405 The question remains, which overlooked parameters could have substantially improved predictive power with respect to basal respiration. It is unlikely, that the POM distribution in space (clustering vs. even distribution) (Schlüter et al., 2019), which in principal could also be analyzed with X-ray CT, would have mattered since the supply with oxygen for basal respiration was sufficient in all samples. Information on microbial diversity such as microbial functional gene abundance related to oxidative and hydrolytic enzymes was recently reported to add another 5-19\% in predictive power and reduce 410 model uncertainty by 55-71\% (Guo et al., 2020). Furthermore, different microbial communities may exert different C mineralization rates due to different carbon use efficiency (Domeignoz-Horta et al., 2020).

The speed of $\mathrm{CO}_{2}$ release $\left(t_{\text {exc }}\right)$ after glucose addition was chosen as an additional target variable to provide a more complete picture of links between microstructural properties and carbon mineralization. The logarithm of this release time was highly correlated with the respiration rate at the beginning of incubation $\left(\log \left(t_{\text {exc }}\right) \sim p_{0}, \mathrm{R}^{2}=0.84\right.$, Fig. $\left.5 \mathrm{~d}\right)$ and total microbial 415 biomass, which is derived from it $\left(T M B, \mathrm{R}^{2}=0.60\right.$, not shown). This causal relationship has to be log-linear, since the substrate is consumed with exponential dynamics after growth sets in, whereas the growth itself seems to be similar for all treatments (in terms of $\mu$ ) indicating similarity in functional structure of microbial community and in intrinsic traits of 
https://doi.org/10.5194/soil-2021-56

Preprint. Discussion started: 22 July 2021

(c) Author(s) 2021. CC BY 4.0 License.

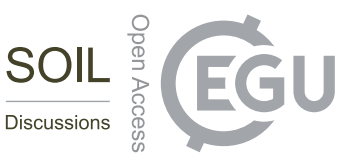

dominating decomposers. In addition, limited oxygen supply at air contents of approx. $0.1 \mathrm{~mm}^{3} \mathrm{~mm}^{-3}$ irrespective of land use (Table 1) likely impaired unlimited aerobic growth and thus inhibited differences in $\mu$. If the growth rate $\mu$, as the second driver of $\mathrm{CO}_{2}$ efflux next to initial activity (in terms of $p_{0}$ or $T M B$ ), would have differed more among soil cores, it would presumably have reduced predictive power of initial microbial biomass and required to take them jointly into account. Maximum microbial specific growth rate for unlimited aerobic growth in sieved, unconsolidated soils is considered as an eco-physiological indicator sensitive to climate conditions (Lipson et al., 2009;Salazar-Villegas et al., 2016), nutrient availability (Loeppmann et al., 2020), soil types (Loeppmann et al., 2018), stages of plant residues decomposition. However, the sensitivity of $\mu$ to different land uses within the same soil type still remains to be tested. Destroying the intact structure is known to have a tremendous impact on microbial activity. Heterotrophic respiration is very different for sieved and intact soil at the same bulk density and soil moisture (Herbst et al., 2016). Our results indicated that also the capacity to grow on glucose is constrained in intact soil structure, presumably by diffusion limitations of the substrate or oxygen. Future studies that focus on this direct comparison will have to clarify this. The prediction of $t_{\text {exc }}$ from independent bulk or pore metrics is still fairly good (all- $p_{0}-r_{0}-\mu$ in Fig. 8, $\mathrm{R}^{2}=0.58$ ) thanks to the correlation of total microbial biomass with POM content $\left(m_{r}\right)$, basal respiration $\left(p_{b}\right)$ and even antecedent water saturation $(\theta / \phi)$ despite being changed by glucose addition (Fig. $\mathrm{S} 2$ ). There are some significant correlations between $t_{e x c}$ and microstructural parameters like $\Gamma, \emptyset, \emptyset_{c}$ and $v_{r}$ (Fig. S 2). However, it is evident that the causal relationship is in fact linked to substrate-induced respiration as a function of total microbial biomass, and that these microstructural properties do not carry any additional information. If only simple bulk properties were used as explanatory variables, then $m_{r}$ was again the most relevant parameter.

\section{Conclusions}

Land use exerted a strong influence on carbon mineralization in terms of basal respiration and glucose-induced respiration. This was mainly caused by the vastly different amount of particulate organic matter in terms of old plant residues and intact roots between grassland and cropland soils. Surprisingly, field water saturation had no effect on basal respiration, as the decomposition of particulate organic matter contributes a large share of $\mathrm{CO}_{2}$ emissions, but is decoupled from the water saturation in the bulk soil. Microstructural properties did not improve the prediction of carbon mineralization, as soil aeration was not limiting carbon mineralization and was maintained by pores that are not resolved with X-ray CT. If strong correlations between microstructural variables and carbon mineralization were observed, then they did not arise from causation but collinearity, and could easily by replaced with cheap bulk properties without substantial loss in predictive 445 power. The POM content was the bulk property that described carbon mineralization best across all land uses under wellaerated conditions. This is likely to change for prolonged phases of high water saturation.

Additional incubation experiments after repeated sampling of the plots at different stages of the growing season and different precipitation history, including the different climate scenarios of the GCEF, will provide a more comprehensive data set in the future. By this, the governing state variables responsible for carbon mineralization vary a lot more due to different soil moisture, different plants within the crop rotation or by seasonally changing shoot-to-root $\mathrm{C}$ allocation ratios. 
https://doi.org/10.5194/soil-2021-56

Preprint. Discussion started: 22 July 2021

(c) Author(s) 2021. CC BY 4.0 License.

(c) (i)

\section{Data availability}

The data are available from the authors upon request.

\section{Author contributions}

SS, EB and ThR designed the research. SS, TR, VG and ThR carried out the experiments. SS. TR, VG, LR, EB and ThR analysed the data. SS, EB and ThR prepared the manuscript with contributions from LR and VG.

\section{Competing interests}

The authors declare that they have no conflict of interest.

\section{Acknowledgement}

We thank the staff of the Bad Lauchstädt Experimental Research Station (especially Ines Merbach and Konrad

Kirsch) and Martin Schädler for their work in in maintaining the plots and infrastructures of the Global Change

Experimental Facility (GCEF), and Harald Auge, François Buscot,

Stefan Klotz, and Martin Schädler for their role in setting up the GCEF.

\section{Competing interests}

The article processing charges for this open-access publication were covered by the Helmholtz Association.

\section{References}

Akimenko, V. K., Trutko, S. M., Medentsev, A. G., and Korobov, V. P.: Distribution of cyanide-resistant respiration among yeasts and bacteria and its relation to oversynthesis of metabolites, Archives of Microbiology, 136, 234-241, 10.1007/BF00409851, 1983.

Altermann, M., Rinklebe, J., Merbach, I., Körschens, M., Langer, U., and Hofmann, B.: Chernozem - Soil of the

Year 2005, Journal of Plant Nutrition and Soil Science, 168, 725-740, 2005.

Anderson, J. P. E., and Domsch, K. H.: A physiological method for the quantitative measurement of microbial biomass in soils, Soil Biology and Biochemistry, 10, 215-221, https://doi.org/10.1016/0038-0717(78)90099-8, 1978.

Auffret, M. D., Karhu, K., Khachane, A., Dungait, J. A. J., Fraser, F., Hopkins, D. W., Wookey, P. A., Singh, B. K.,

Freitag, T. E., Hartley, I. P., and Prosser, J. I.: The Role of Microbial Community Composition in Controlling Soil Respiration Responses to Temperature, PLOS ONE, 11, e0165448, 10.1371/journal.pone.0165448, 2016.

Blagodatskaya, E., and Kuzyakov, Y.: Active microorganisms in soil: Critical review of estimation criteria and approaches, Soil Biology and Biochemistry, 67, 192-211, https://doi.org/10.1016/i.soilbio.2013.08.024, 2013. Bouckaert, L., Sleutel, S., Van Loo, D., Brabant, L., Cnudde, V., Van Hoorebeke, L., and De Neve, S.: Carbon mineralisation and pore size classes in undisturbed soil cores, Soil Research, 51, 14-22, https://doi.org/10.1071/SR12116, 2013.

Buades, A., Coll, B., and Morel, J.-M.: A non-local algorithm for image denoising. In: Computer Vision and Pattern Recognition, 2005. CVPR 2005. IEEE Computer Society Conference on, San Diego, California, 2005. Canty, A., and Ripley, B.: boot: Bootstrap R (S-Plus) Functions . R package version 1.3-24, 2019. 
https://doi.org/10.5194/soil-2021-56

Preprint. Discussion started: 22 July 2021

(c) Author(s) 2021. CC BY 4.0 License.

\section{(c) (i)}

485 Davidson, E. A., Janssens, I. A., and Luo, Y.: On the variability of respiration in terrestrial ecosystems: moving beyond Q10, Global Change Biology, 12, 154-164, https://doi.org/10.1111/j.1365-2486.2005.01065.x, 2006. Davison, A. C., and Hinkley, D. V.: Bootstrap methods and their application, Cambridge Series in Statistical and Probabilistic Mathematics, Cambridge University Press, Cambridge, 1997.

de Mendiburu, F.: Agricolae: statistical procedures for agricultural research. In: R package version, 2019.

De Neve, S., and Hofman, G.: Influence of soil compaction on carbon and nitrogen mineralization of soil organic matter and crop residues, Biology and Fertility of Soils, 30, 544-549, 10.1007/s003740050034, 2000.

Domeignoz-Horta, L. A., Pold, G., Liu, X.-J. A., Frey, S. D., Melillo, J. M., and DeAngelis, K. M.: Microbial diversity drives carbon use efficiency in a model soil, Nature Communications, 11, 3684, 10.1038/s41467-020-17502-z, 2020.

495 Dungait, J. A. J., Hopkins, D. W., Gregory, A. S., and Whitmore, A. P.: Soil organic matter turnover is governed by accessibility not recalcitrance, Global Change Biology, 18, 1781-1796, doi:10.1111/j.1365-2486.2012.02665.x, 2012.

Ebrahimi, A., and Or, D.: On Upscaling of Soil Microbial Processes and Biogeochemical Fluxes From Aggregates to Landscapes, Journal of Geophysical Research: Biogeosciences, 123, 1526-1547, doi:10.1029/2017JG004347, 2018.

Eden, M., Moldrup, P., Schjønning, P., Vogel, H.-J., Scow, K. M., and de Jonge, L. W.: Linking Soil Physical Parameters Along a Density Gradient in a Loess-Soil Long-Term Experiment, Soil Science, 177, 1-11, 10.1097/SS.0b013e31823745a9, 2012.

Efron, B.: Better bootstrap confidence intervals, Journal of the American Statistical Association, 82, 171-185, https://doi.org/10.2307/2289144, 1987.

Guo, X., Gao, Q., Yuan, M., Wang, G., Zhou, X., Feng, J., Shi, Z., Hale, L., Wu, L., Zhou, A., Tian, R., Liu, F., Wu, B., Chen, L., Jung, C. G., Niu, S., Li, D., Xu, X., Jiang, L., Escalas, A., Wu, L., He, Z., Van Nostrand, J. D., Ning, D., Liu, X., Yang, Y., Schuur, E. A. G., Konstantinidis, K. T., Cole, J. R., Penton, C. R., Luo, Y., Tiedje, J. M., and Zhou, J.: Geneinformed decomposition model predicts lower soil carbon loss due to persistent microbial adaptation to warming, Nature Communications, 11, 4897, 10.1038/s41467-020-18706-z, 2020.

Herbst, M., Tappe, W., Kummer, S., and Vereecken, H.: The impact of sieving on heterotrophic respiration response to water content in loamy and sandy topsoils, Geoderma, 272, 73-82, https://doi.org/10.1016/i.geoderma.2016.03.002, 2016.

Hund, K., and Schenk, B.: The microbial respiration quotient as indicator for bioremediation processes,

515 Chemosphere, 28, 477-490, https://doi.org/10.1016/0045-6535(94)90292-5, 1994.

Juarez, S., Nunan, N., Duday, A.-C., Pouteau, V., and Chenu, C.: Soil carbon mineralisation responses to alterations of microbial diversity and soil structure, Biology and Fertility of Soils, 49, 939-948, 10.1007/s00374013-0784-8, 2013.

Kemmitt, S. J., Lanyon, C. V., Waite, I. S., Wen, Q., Addiscott, T. M., Bird, N. R. A., O’Donnell, A. G., and Brookes,

520 P. C.: Mineralization of native soil organic matter is not regulated by the size, activity or composition of the soil microbial biomass-a new perspective, Soil Biology and Biochemistry, 40, 61-73, https://doi.org/10.1016/i.soilbio.2007.06.021, 2008.

Koestel, J.: SoilJ: An ImageJ Plugin for the Semiautomatic Processing of Three-Dimensional X-ray Images of Soils, Vadose Zone Journal, 17, 10.2136/vzj2017.03.0062, 2018.

525 Kravchenko, A. N., Toosi, E. R., Guber, A. K., Ostrom, N. E., Yu, J., Azeem, K., Rivers, M. L., and Robertson, G. P.: Hotspots of soil N2O emission enhanced through water absorption by plant residue, Nature Geoscience, 10, 496, 10.1038/ngeo2963 
https://doi.org/10.5194/soil-2021-56

Preprint. Discussion started: 22 July 2021

(c) Author(s) 2021. CC BY 4.0 License.

(c) (i)

https://www.nature.com/articles/ngeo2963\#supplementary-information, 2017.

Kravchenko, A. N., Guber, A. K., Razavi, B. S., Koestel, J., Quigley, M. Y., Robertson, G. P., and Kuzyakov, Y.:

Microbial spatial footprint as a driver of soil carbon stabilization, Nature Communications, 10, 3121,

10.1038/s41467-019-11057-4, 2019.

Kuzyakov, Y., Blagodatskaya, E., and Blagodatsky, S.: Comments on the paper by Kemmitt et al. (2008)

'Mineralization of native soil organic matter is not regulated by the size, activity or composition of the soil microbial biomass - A new perspective' [Soil Biology \& Biochemistry 40, 61-73]: The biology of the Regulatory Gate, Soil Biology and Biochemistry, 41, 435-439, https://doi.org/10.1016/j.soilbio.2008.07.023, 2009.

Legland, D., Arganda-Carreras, I., and Andrey, P.: MorphoLibJ: integrated library and plugins for mathematical morphology with ImageJ, Bioinformatics, 32, 3532-3534, 2016.

Lehmann, J., Hansel, C. M., Kaiser, C., Kleber, M., Maher, K., Manzoni, S., Nunan, N., Reichstein, M., Schimel, J. P., Torn, M. S., Wieder, W. R., and Kögel-Knabner, I.: Persistence of soil organic carbon caused by functional complexity, Nature Geoscience, 13, 529-534, 10.1038/s41561-020-0612-3, 2020.

Liebig, M. A., Jones, A. J., Doran, J. W., and Mielke, L. N.: Potential Soil Respiration and Relationship to Soil

Properties in Ridge Tillage, Soil Science Society of America Journal, 59, 1430-1435, https://doi.org/10.2136/sssaj1995.03615995005900050032x, 1995.

Lipson, D. A., Monson, R. K., Schmidt, S. K., and Weintraub, M. N.: The trade-off between growth rate and yield

545 in microbial communities and the consequences for under-snow soil respiration in a high elevation coniferous forest, Biogeochemistry, 95, 23-35, 10.1007/s10533-008-9252-1, 2009.

Loeppmann, S., Semenov, M., Kuzyakov, Y., and Blagodatskaya, E.: Shift from dormancy to microbial growth revealed by RNA:DNA ratio, Ecological Indicators, 85, 603-612, https://doi.org/10.1016/j.ecolind.2017.11.020, 2018.

550 Loeppmann, S., Breidenbach, A., Spielvogel, S., Dippold, M. A., and Blagodatskaya, E.: Organic Nutrients Induced Coupled C- and P-Cycling Enzyme Activities During Microbial Growth in Forest Soils, Frontiers in Forests and Global Change, 3, 10.3389/ffgc.2020.00100, 2020.

Meurer, K. H. E., Chenu, C., Coucheney, E., Herrmann, A. M., Keller, T., Kätterer, T., Nimblad Svensson, D., and Jarvis, N.: Modelling dynamic interactions between soil structure and the storage and turnover of soil organic

555 matter, Biogeosciences, 17, 5025-5042, 10.5194/bg-17-5025-2020, 2020.

Nazaries, L., Tottey, W., Robinson, L., Khachane, A., Al-Soud, W. A., Sørensen, S., and Singh, B. K.: Shifts in the microbial community structure explain the response of soil respiration to land-use change but not to climate warming, Soil Biology and Biochemistry, 89, 123-134, https://doi.org/10.1016/j.soilbio.2015.06.027, 2015. Otsu, N.: A threshold selection method from gray-level histograms, Automatica, 11, 23-27, 1975.

560 Palm, C., Blanco-Canqui, H., DeClerck, F., Gatere, L., and Grace, P.: Conservation agriculture and ecosystem services: An overview, Agriculture, Ecosystems \& Environment, 187, 87-105, 2014.

Panikov, N.: Microbial Growth Kinetics. Chapman \& Hall. London-Glasgow-Weinheim, 1995.

Perkons, U., Kautz, T., Uteau, D., Peth, S., Geier, V., Thomas, K., Lütke Holz, K., Athmann, M., Pude, R., and Köpke, U.: Root-length densities of various annual crops following crops with contrasting root systems, Soil and

565 Tillage Research, 137, 50-57, https://doi.org/10.1016/i.still.2013.11.005, 2014.

Poeplau, C., and Don, A.: Sensitivity of soil organic carbon stocks and fractions to different land-use changes across Europe, Geoderma, 192, 189-201, https://doi.org/10.1016/i.geoderma.2012.08.003, 2013.

R Core Team: R: A language and environment for statistical computing. R Foundation for Statistical Computing, Vienna, Austria. URL https://www.R-project.org/, 2018. 
https://doi.org/10.5194/soil-2021-56

Preprint. Discussion started: 22 July 2021

(c) Author(s) 2021. CC BY 4.0 License.

\section{(c) (1)}

570 Rawlins, B. G., Wragg, J., Reinhard, C., Atwood, R. C., Houston, A., Lark, R. M., and Rudolph, S.: Threedimensional soil organic matter distribution, accessibility and microbial respiration in macroaggregates using osmium staining and synchrotron $\mathrm{X}$ ray computed tomography, SOIL, 2, 659-671, 10.5194/soil-2-659-2016, 2016.

Roger-Estrade, J., Richard, G., Caneill, J., Boizard, H., Coquet, Y., Defossez, P., and Manichon, H.: Morphological

575 characterisation of soil structure in tilled fields: from a diagnosis method to the modelling of structural changes over time, Soil \& Tillage Research, 79, 33-49, 2004.

Salazar-Villegas, A., Blagodatskaya, E., and Dukes, J. S.: Changes in the Size of the Active Microbial Pool Explain Short-Term Soil Respiratory Responses to Temperature and Moisture, Frontiers in Microbiology, 7, 10.3389/fmicb.2016.00524, 2016.

580 Schädler, M., Buscot, F., Klotz, S., Reitz, T., Durka, W., Bumberger, J., Merbach, I., Michalski, S. G., Kirsch, K., Remmler, P., Schulz, E., and Auge, H.: Investigating the consequences of climate change under different landuse regimes: a novel experimental infrastructure, Ecosphere, 10, e02635, https://doi.org/10.1002/ecs2.2635, 2019.

Schindelin, J., Arganda-Carreras, I., Frise, E., Kaynig, V., Longair, M., Pietzsch, T., Preibisch, S., Rueden, C.,

585 Saalfeld, S., and Schmid, B.: Fiji: an open-source platform for biological-image analysis, Nature methods, 9, 676682, 2012.

Schlüter, S., Vogel, H.-J., Ippisch, O., and Vanderborght, J.: Combined Impact of Soil Heterogeneity and Vegetation Type on the Annual Water Balance at the Field Scale, Vadose Zone Journal, 12, 2013.

Schlüter, S., Sheppard, A., Brown, K., and Wildenschild, D.: Image processing of multiphase images obtained via

X-ray microtomography: A review, Water Resources Research, 50, 3615-3639, 2014.

Schlüter, S., Zawallich, J., Vogel, H. J., and Dörsch, P.: Physical constraints for respiration in microbial hotspots in soil and their importance for denitrification, Biogeosciences Discuss., 2019, 1-31, 10.5194/bg-2019-2, 2019. Schlüter, S., Albrecht, L., Schwärzel, K., and Kreiselmeier, J.: Long-term effects of conventional tillage and notillage on saturated and near-saturated hydraulic conductivity - Can their prediction be improved by pore

595 metrics obtained with X-ray CT?, Geoderma, 361, 114082, https://doi.org/10.1016/j.geoderma.2019.114082, 2020.

Schmidt, M. W. I., Torn, M. S., Abiven, S., Dittmar, T., Guggenberger, G., Janssens, I. A., Kleber, M., KögelKnabner, I., Lehmann, J., Manning, D. A. C., Nannipieri, P., Rasse, D. P., Weiner, S., and Trumbore, S. E.: Persistence of soil organic matter as an ecosystem property, Nature, 478, 49-56, 2011.

600 Sommer, C., Straehle, C., Köthe, U., and Hamprecht, F. A.: Ilastik: Interactive learning and segmentation toolkit, 2011 IEEE International Symposium on Biomedical Imaging: From Nano to Macro, 2011, 230-233, Stenström, J., Stenberg, B., and Johansson, M.: Kinetics of Substrate-Induced Respiration (SIR): Theory, Ambio, 27, 35-39, 1998.

Strudley, M. W., Green, T. R., and Ascough, J. C.: Tillage effects on soil hydraulic properties in space and time:

605 State of the science, Soil and Tillage Research, 99, 4-48, 2008.

Thorup-Kristensen, K., Salmerón Cortasa, M., and Loges, R.: Winter wheat roots grow twice as deep as spring wheat roots, is this important for $\mathrm{N}$ uptake and $\mathrm{N}$ leaching losses?, Plant and Soil, 322, 101-114, 2009.

Vogel, H.-J., Weller, U., and Schlüter, S.: Quantification of soil structure based on Minkowski functions, Computers \& Geosciences, 36, 1236-1245, 2010.

610 Wardle, D. A., and Ghani, A.: A critique of the microbial metabolic quotient (qCO2) as a bioindicator of disturbance and ecosystem development, Soil Biology and Biochemistry, 27, 1601-1610, https://doi.org/10.1016/0038-0717(95)00093-T, 1995. 
https://doi.org/10.5194/soil-2021-56

Preprint. Discussion started: 22 July 2021

(C) Author(s) 2021. CC BY 4.0 License.

SOLL EGE

Wickham, H.: ggplot2: Elegant Graphics for Data Analysis. Springer-Verlag New York, 2016.

Wolodzko, T.: Kernelboot: Smoothed bootstrap and random generation from kernel densities, 2020.

615 Wutzler, T., Blagodatsky, S. A., Blagodatskaya, E., and Kuzyakov, Y.: Soil microbial biomass and its activity estimated by kinetic respiration analysis - Statistical guidelines, Soil Biology and Biochemistry, 45, 102-112, https://doi.org/10.1016/i.soilbio.2011.10.004, 2012.

Yan, Z., Bond-Lamberty, B., Todd-Brown, K. E., Bailey, V. L., Li, S., Liu, C., and Liu, C.: A moisture function of soil heterotrophic respiration that incorporates microscale processes, Nature Communications, 9, 2562,

620 10.1038/s41467-018-04971-6, 2018. 